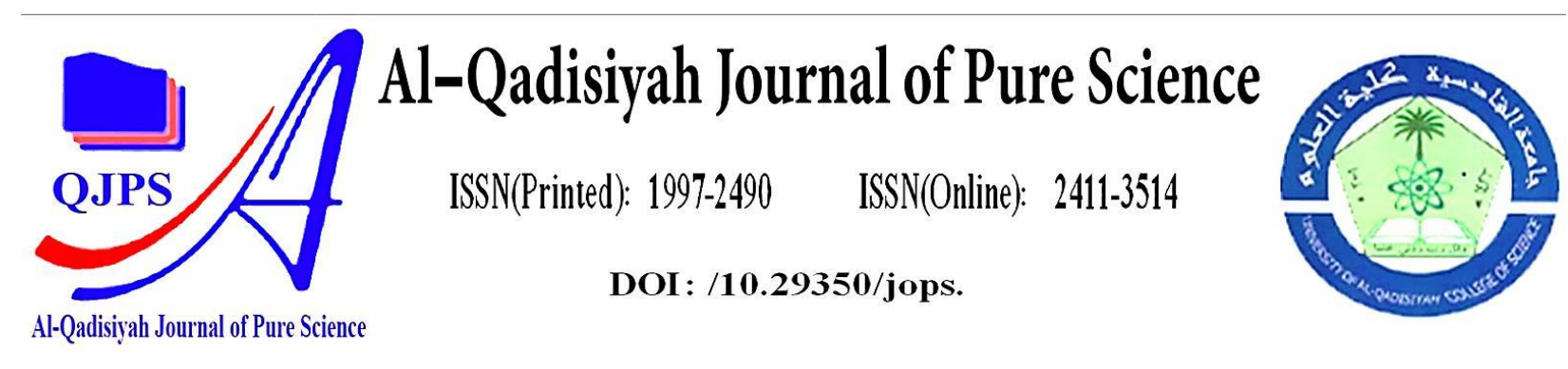

\title{
Effect sleep deprivation on some liver enzymes for adult's males
}

\begin{tabular}{|c|c|}
\hline Authors Names & ABSTRACT \\
\hline $\begin{array}{l}\text { Article History } \\
\text { Received on: 20/6/2021 } \\
\text { Revised on: 30/7/2021 } \\
\text { Accepted on : 22/8/2021 } \\
\text { Keywords: } \\
\text { Sleep deprivation, liver } \\
\text { enzymes }\end{array}$ & $\begin{array}{l}\text { The current study was designed for two groups, each group contain (20) } \\
\text { nonsmokers healthy persons males, first group was get (more than } 7 \text { hours } \\
\text { sleep / day), while the second group did not get enough sleep hours (less } \\
\text { than } 7 \text { hours sleep / day). The results showed a significant increase in the } \\
\text { level of body mass index (BMI), the activity of glutamic pyruvic } \\
\text { transaminase enzyme (GPT), glutamic oxaloacetic transaminase enzyme } \\
\text { (GOT) and concentration of total serum bilirubin (TSB) at probability } \\
\text { level ( } \mathrm{P} \leq 0.049, \mathrm{P} \leq 0.047, \mathrm{P} \leq 0.032, \mathrm{P} \leq 0.035 \text { ) Respectively in Persons } \\
\text { with second group compared to Persons with first group, as well as the } \\
\text { study showed a positive correlation between the studied parameters, with }\end{array}$ \\
\hline $\begin{array}{l}\text { DOI: https://doi.org/10.29350/ } \\
\text { jops.2021.26. } 4.1377\end{array}$ & $\begin{array}{l}\text { increase of all parameters in the second group with each other as a result } \\
\text { of the same reason. }\end{array}$ \\
\hline
\end{tabular}

\section{Introduction}

Sleep deprivation can be defined a lack of sleep through a certain interval less-than optimal sleep time. There are many reasons for inadequate sleep which affects in significant number of people like modern life existence and work-related factors. A chronic reduction in the sleep time or the division of sleep, causes the disruption of the sleep cycle [3].A good sleep is one of the more useful human experiences with important in keeping good attitude and mental acuity as well as in stimulating physiologic balance and resilience. People spend about one-third of their lives sleep, sleep deficiency causes stressor on brain and many body systems [8], Reported consequences of inadequate sleep comprise neurocognitive changes, psychomotor deficiency, adverse mood effects, uncomfortable life, reduced work yield, shortfalls in memory and making the decision [10], and associated with self-rated deprived health and raised body mass index (BMI) [14], Also reasons to reduction in liver catalase and glutathione activity without compensative rises in other enzymatic antioxidants [2], there is a it prevents synchronization of cellular role, which inevitably leads to metabolic disorders as sleep lack results in not compensated oxidative stress [9].Oxidative stress is an discrepancy among the realization and removal of reactive oxygen species / nitrogen species and is connected with more than a few adverse results such as cancer, lack of immune system, neural and cardiac diseases [17], Some experimental on rats showed that inadequate sleep leads to histological and pathological damages in the liver, kidney and heart [15]. The researchers found inadequate sleep could be the main reason for abnormal in the activity of serum aminotransferase enzymes and nonalcoholic fatty liver disease [4]. High levels of enzymes superoxide dismutase, glutathione peroxidase, glutamic pyruvic transaminase and glutamic oxaloacetic transaminase and malondialdehyde in rats deprived for 72 hours of sleep continuously [16]. Glutamic pyruvic transaminase (GPT) ( 
E.C.2.6.1.2) and glutamic oxaloacetic transaminase (GOT) (E.C.2.6.1.1) are enzymes found generally in the liver, but likewise found in red blood cells, cardiac cells, muscle tissue and many organs. (GPT, GOT) also called (ALT, AST) (alanine aminotransferase, aspartate aminotransferase) respectively. GOT or GPT level are respected assistance mainly in the identification of liver disease or liver damaged are released into the bloodstream, the amount of GPT and GOT in the blood is directly linked to the level of the tissue damage [11] [1]. Bilirubin is a laboratory test usually used for patient care, mainly newborn patients and patients with anemia or supposed liver syndromes and that test is linked with sleep pattern and oxidative stress [5].

The aim of the study: This study aiming to predict probability of liver damage due to inadequate sleep in healthy persons who did not get enough sleep compering with persons who get enough sleep hours.

\section{Materials and methods}

This study included (25) blood samples of nonsmokers healthy persons males with range sleep hours of (7-9/day), ages categories between (22-66) years, and (25) blood samples of nonsmokers healthy persons males with range sleep hours between of (2-6/day), ages ranged between (24-67) years also. Five milliliters $(\mathrm{mL})$ of venous blood were collected into plain tubes from each cases. The blood samples were allowed to stand for 15 minutes ( $\mathrm{min}$ ) then centrifuged at $4000 \mathrm{~g}$ for $10 \mathrm{~min}$. Serum was frozen at $-20^{\circ} \mathrm{C}$ till used for the estimation of GPT, GOT and TSB.

\section{Estimation of biochemical parameters in the serum blood}

The activity of the glutamic oxaloacetic transaminase enzyme (GOT), glutamic pyruvic transaminase enzyme (GPT) and the total serum bilirubin (TSB) concentration estimated by using (Kits) supplied by the French company (Biolab). BMI is believed as a predictor of obesity and generally regarded as tool for measuring obesity. (BMI) was calculated according to the equation.

$B M I=\frac{\text { Weight }(\mathrm{kg})}{\text { Hight }(\mathrm{m})^{2}}$

Depending on World Health Organization, the body mass index falls into the following criteria for (adults older than 20 years), as follows (less than $18.5 \mathrm{~kg} / \mathrm{m}^{2}$ underweight), (18.5-25 $\mathrm{kg} / \mathrm{m}^{2}$ normal), (25-30 kg / $\mathrm{m}^{2}$ overweight) and (more than $30 \mathrm{~kg} / \mathrm{m}^{2}$ obesity) [18], and in this study followed same criteria.

\section{Statistical analysis}

The mean and standard error were found for clinical parameters studied with the (t-test) to compare two groups. The relationship between the studied parameters was also found by finding the value of the correlation coefficient by using the statistical analysis program (SPSS 18).

\section{Results and discussion}

Liver markers are an indication of liver health and normal functioning (11). It is found in Table (1) below.

Table (1) compared between liver markers and (BMI) in studied groups

\begin{tabular}{|c|c|c|c|c|}
\hline details & Sleep hours & $\mathrm{N}$ & Mean \pm SE & P-Value \\
\hline Barameters & & & & \\
\cline { 1 - 4 } & More than 7 & 25 & $26.95 \pm 0.76$ & \multirow{2}{*}{0.049} \\
\cline { 2 - 5 } & Less than 7 & 25 & $29.22 \pm 0.51$ & \\
\hline GPT(U/I) & More than 7 & 25 & $27.57 \pm 1.04$ & 0.047 \\
\hline
\end{tabular}




\begin{tabular}{|c|c|c|c|c|}
\hline & Less than 7 & 25 & $33.66 \pm 2.70$ & \\
\hline \multirow{2}{*}{ GOT(U/I) } & More than 7 & 25 & $21.75 \pm 2.28$ & \multirow{2}{*}{0.032} \\
\cline { 2 - 4 } & Less than 7 & 25 & $29.01 \pm 3.02$ & \\
\hline \multirow{2}{*}{$\mathrm{TSB}(\mu \mathrm{mol} / \mathrm{L})$} & More than 7 & 25 & $14.45 \pm 2.80$ & \multirow{2}{*}{0.035} \\
\cline { 2 - 4 } & Less than 7 & 25 & $28.14 \pm 5.86$ & \\
\hline
\end{tabular}

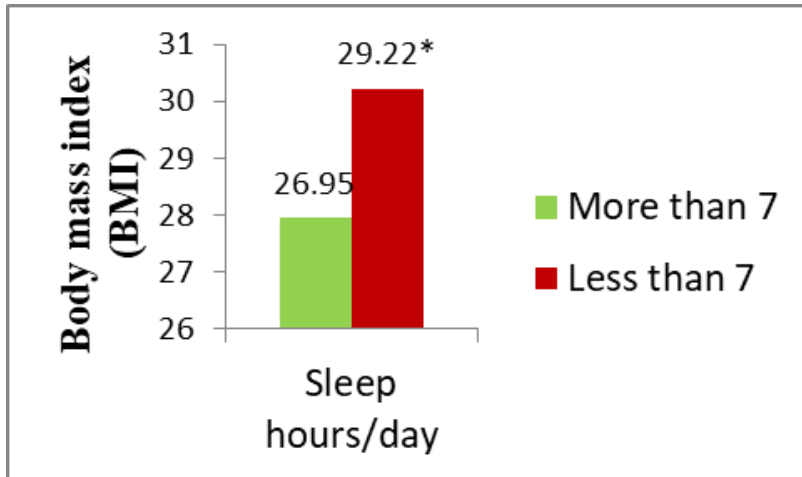

(Figure 1) Compared between body mass index (BMI).

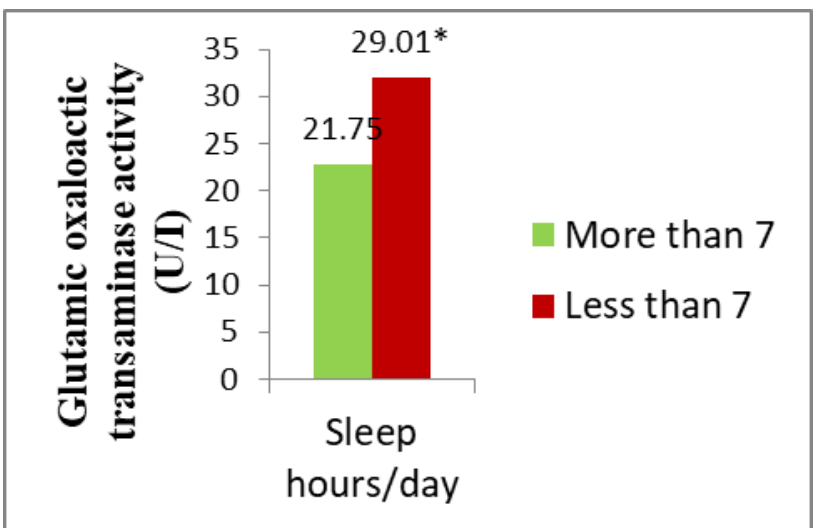

(Figure 3) Compared between glutamic oxaloacetic transaminase activity (GOT)

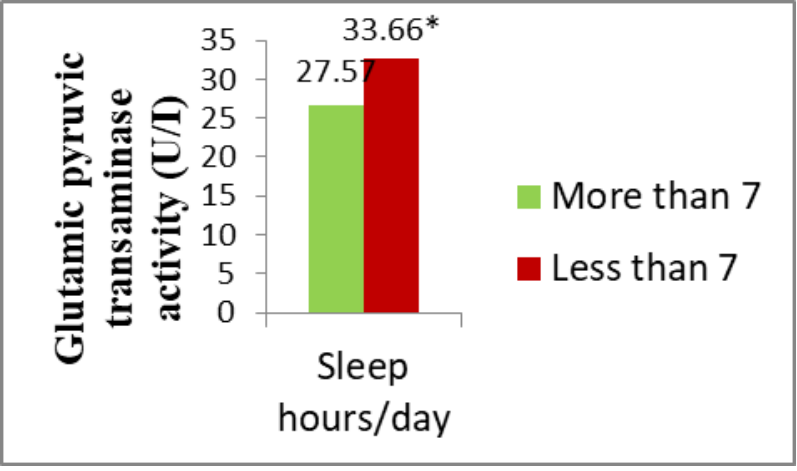

(Figure 2) Compared between glutamic pyruvic transaminase activity (GPT)

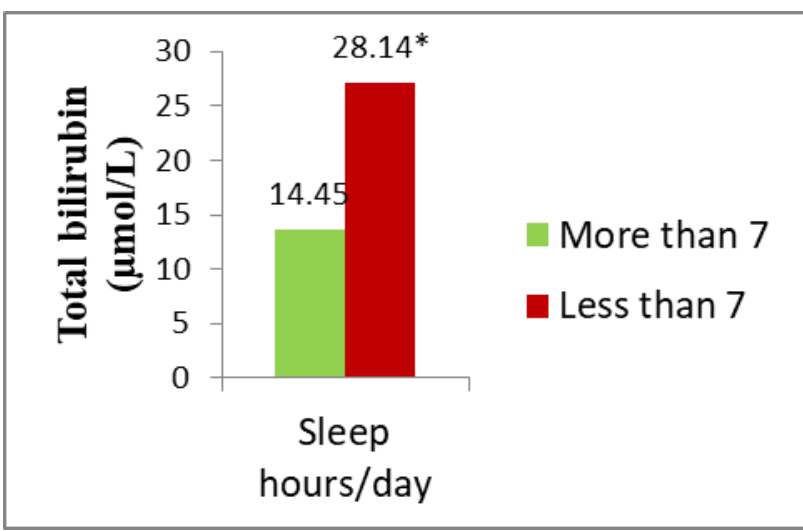

(Figure 4) Compared between concentration total serum bilirubin (TSB)

The results showed significant increase in the body mass index (BMI) for Persons who got sleep hours less than 7 hours/day compared to Persons who got sleep hours more than 7 hours/day, as shown in the table (1) and figure (1), this is an agreement with the results that gained by authors, (the sleep duration of less than 6 hours a day contributes to obesity and overweight) [13].

The results appeared significant increase in activity of the glutamic pyruvic transaminase enzyme (GPT) in Persons who did not get enough daily sleep hours (less than 7 hours/day) 
compared to Persons who enjoyed this amount of enough sleep hours (more than 7 hours/day) as shown in Table (1) and Figure (2). This results agreed with authors results who found that 72hour sleep partial deprivation in rats leads to an increase in the level of glutamic pyruvic transaminase activity (GPT) [6]. And authors results when they are effect of inadequate sleeping hours (2-6) hours / day duration 21 days causes evaluation of glutamic pyruvic transaminase activity in rats experimental [7].

The results showed a significant increase in the activity of the enzyme glutamic oxaloacetic transaminase (GOT) in persons who did not get enough daily sleep hours (less than 7 hours) compared to persons who enjoyed enough daily sleep hours (more than 7 hours) as shown in Table (1) and Figure (3), and these results accepted with authors who found, that inadequate sleep causes an increase in the level of activity of the glutamaic oxaloactic transaminase (GOT) [12]. Also authors found an increase in the activity of the glutamic oxaloacetic transaminase (GOT) in rats that were 21 days given hours' sleep for 2-6 hours / day in rats experimental [7].

Results showed a significant increase in the concentration of total serum bilirubin (TSB) in persons who suffer from lack in daily optimum sleep hours (less than 7 hours) compared with persons who have optimum daily sleep hours (more than 7 hours) as shown in the table (1) and the figure (4) and these results agreed with authors results who found that the inadequate sleep related with increase total serum bilirubin concentration (TSB) [5].

Table (2) indicate the correlations between studied parameters with each other. The table below indicates the existence of positive correlation between each of the glutamic pyruvic transaminase (GPT), glutamic oxaloactic transaminase (GOT), total serum bilirubin (TSB) and body mass index (BMI) with each other, but this relationship was non-significance, except (GOT) with (BMI) correlation which it was significant statically, these results refer to the effects of (inadequate sleep hours / day) and generally affected towards increasing the amounts of studied parameters.

\section{(Table 2) correlation between the studied parameters}

\begin{tabular}{|c|c|c|}
\hline BMI & & \\
\hline $\begin{array}{c}0.036 \\
\text { N.S }\end{array}$ & GPT & \\
\hline $\begin{array}{c}0.714 \\
P \leq 0.05\end{array}$ & $\begin{array}{c}0.372 \\
\text { N.S }\end{array}$ & GOT \\
\hline $\begin{array}{l}0.504 \\
\text { N.S }\end{array}$ & $\begin{array}{c}0.238 \\
\text { N.S }\end{array}$ & $\begin{array}{c}0.629 \\
\text { N.S }\end{array}$ \\
\hline
\end{tabular}

\section{Conclusion}

Conclusion from this study: Depending on results of this study, the inadequate sleep is strong probable of liver damage in the future for healthy persons.

Conflict of Interest: The authors declare that they have no conflict of interest. 


\section{Acknowledgements:}

We are very gratefull for the continuous support and encouragement made by the University of Kirkuk and Kirkuk health directorate and the College of Sciences, University of Al-Qadisiyah.We also deeply thank the locals and persons who helped us during the work

\section{References:}

1. Bikha, R. D.; Aneela, A.; Syed, Z. A. and Ghulam, A. O.(2012) "Serum Trace Metals and Enzyme Activity in Patients with Hepatic Encephalopathy" World Applied Sciences Journal . 16(8):1053-1059.

2. Everson, C.; Laatsch, C. and Hogg, N. (2005)"Antioxidant defense responses to sleep loss and sleep recovery”.Am J Physiol Regul Integr Comp Physiol. 288(2):R374-383.

3. Gryglewska, O. (2010) "Consequences of sleep deprivation" Int J Occup Med Environ Health. 23(1):95-114.

4. Kim,D.; Kim,H.J ; Kushida,C.A; Heo,N.Y; Ahmed,A. and Kim,W.R.(2018) "Short Sleep Duration Is Associated With Abnormal Serum Aminotransferase Activities and Nonalcoholic Fatty Liver Disease" Clin Gastroenterol Hepatol. 16(4):588-590

5. Larsoon , A.;Hasan , M.; Ridefelt, B.; Axelsson, J.(2009)" Circadian variability of bilirubin in healthy men during normal sleep and after an acute shift of sleep" Chronobiol Int.26(8):1613-21

6. Li, T.; Cao, R.; Xia, R.; and Zhongyuan Xia, Z.(2017) “Effects of 72 Hours Sleep Deprivation on Liver Circadian Clock Gene Expression and Oxidative Stress in Rats". Yangtze Medicine.1:194-201

7. Li , Y.; Zhang , Y.; Ji , G.; Shen, Y.; Zhao,N.; Y Liang,Y.; Wang ,Z.; Liu, M.; and Lin , L.(2020)" Autophagy Triggered by Oxidative Stress Appears to Be Mediated by the AKT/mTOR Signaling Pathway in the Liver of SleepDeprived Rats" Oxidative Medicine and Cellular Longevity Volume 2020, Article ID 6181630, 11 pages

8. Maurovich-Horvat, E.; Pollmächer, T.Z and Sonka, K.(2008)" The effects of sleep and sleep deprivation on metabolic, endocrine and immune parameters" Prague Med. Rep. 109(4):275-85.

9. McEwen, B. (2006)" Sleep deprivation as a neurobiologic and physiologic stressor: Allostasis and allostatic load: Metabolism. 55(10 Suppl 2):S20-3

10.Noguti, J.; Anderson, M.L.; Cirelli, C. and Riberio, D.A. (2013)" Oxidative stress, cancer, and sleep deprivation: Is there a logical link in this association?" Sleep and Breathing .17(3): 905-910.

11.Paul, T. and Giboney, M. D. (2005)" Mildly Elevated liver Transaminase levels in the Asymptomatic Patient". American Family Physician .71(6): p.1105-10

12.Periasamy, S.; Hsu, D. Z.; Fu, Y.H. And Liu, M.Y. (2015)" Sleep deprivation-induced multi-organ injury: role of oxidative stress and inflammation" EXCLI Journal. 14: 672683

13.Rathod, S.S.; Nagose,V.B.; Kanagala,A.; Bhuvangiri,H.; Kanneganti,J. and Annepaka , E.(2018) "Sleep duration and its association with obesity and overweight in medical students: A cross-sectional study". National Journal of Physiology, Pharmacy and Pharmacology. 8(1): 113-117 
14.Steptoe, A.; Peacey, V. and Wardle, J. (2006) "Sleep duration and health in young adults"Arch Intern Med. 166:1689-1692.

15.Taha,M; ,Hagar Y. Rady, H.Y.; Nouran K. and Olama, N.K.(2018)"Effect of sleep deprivation on the liver, kidney and heart: histological and immunohistochemical study "Int J Sci Rep. 4(7):172-181

16.Tang, L.; Ruina, C.; Rui, X. and Zhongyuan, X. (2017)"Effects of 72 Hours Sleep Deprivation on Liver Circadian Clock Gene Expression and Oxidative Stress in Rats" Yangtze Medicine. 1(4): 194-201

17.Turrens, J.(2003) “ Mitochondrial formation of reactive oxygen species”J. Physiol. 552(2):335-44

18. World Health Organization.(2006) "BMI Classification". Global Database on Body Mass Index. 2006. Available from: Http: // www .apps. Who int /bmi /index. jsp?introPage=intro_3.html. [Last accessed on 2017 Sep 28] 